\section{International Scientific Journal Theoretical \& Applied Science}

\author{
p-ISSN: 2308-4944 (print) e-ISSN: 2409-0085 (online) \\ Year: 2016 Issue: 11 Volume: 43 \\ Published: 24.11.2016 http://T-Science.org
}

\begin{abstract}
Master of Engineering and Technology, Corresponding Member of International Academy of Theoretical and Applied Sciences, Lecturer of Vladimir Industrial College, Russian Federation chemezov-da@yandex.ru
\end{abstract}

SECTION 7. Mechanics and machine construction.

\title{
THE SOLUTION OF THE HEAT TRANSFER PROBLEM IN THE ELMER SOFTWARE
}

\author{
Abstract: In article is given an idea of computer simulation of the heat transfer in solid bodies by the finite \\ element method. By means of the mathematical package Elmer FEM solver the analysis of the temperature field \\ model of the first compression piston ring during vehicle operation is made. \\ Key words: simulation, temperature, a compression piston ring. \\ Language: English \\ Citation: Chemezov D (2016) THE SOLUTION OF THE HEAT TRANSFER PROBLEM IN THE ELMER \\ SOFTWARE. ISJ Theoretical \& Applied Science, 11 (43): 111-117. \\ Soi: http://s-o-i.org/1.1/TAS-11-43-20 Doi: crossef http://dx.doi.org/10.15863/TAS.2016.11.43.20
}

\section{Introduction}

A computer program Elmer FEM solver is used in mathematical modeling of physical processes in 2D or 3D formulation $[1 ; 2]$. As in most similar software in Elmer the finite element partitioning of the investigated models is implemented.

In ElmerGUI module [3] are constructed or loaded models and in automated mode they are partitioned into finite elements. Perhaps the solution to the problems of electromagnetism (electrostatics, magnetostatics, induction), heat transfer (heat conduction equation, radiation, convection, phase transitions), structural mechanics (general equations of elasticity, models for PCBs and shells), fluid dynamics (Navier-Stokes equation, Stokes and Reynolds equation, k- $\varepsilon$ model), acoustics (Helmholtz equations, linearized time-harmonic approximation) and etc.

For linear system the calculation can be performed by three methods: direct - Banded, Umfpack, MUMPS (multifrontal massively parallel solver); iterative - BiCGStab (biconjugate gradients stabilized method), BiCGStabl (biconjugate gradients stabilized (l) method), TFQMR (transpose-free quasi-minimal residual method), GCR (generalized conjugate residual), CGS (conjugate gradient squared), CG (conjugate gradient), GMRES (generalized minimum residual method with restarts) and multigrid - Jacobi, CG, BiCGStab. The control of preconditioning is performed by the following algorithms: Diagonal, Multigrid, ILU0 - ILU9 (incomplete LU), ILUT (incomplete LU with threshold), vanka.

For solving large sparse systems of linear algebraic equations on high-performance parallel systems the Hypre library is used. The calculation is performed by ParaSails and BoomerAMG solvers. In the solver BoomerAMG it is possibly the choice of methods: relaxation (Jabobi, Gauss-Seiden sequential, Gauss-Seidel interior in parallel, Hybrid Gauss-Seidel or SOR forward, Hybrid Gauss-Seidel or SOR backward, Hybrid chaotic Gauss-Seidel, Hybrid symmetric Gauss-Seidel or SSOR, Gaussian elimination); coarsening (CLJP, Ruge-Stueben w/o (with) bndry treatment, Falgout, PMIS, HMIS, Onepass Ruge-Stueben, CGC, CGC-E); interpolation (Classical modified, LS, Classical modified for hyperpolic PDEs, Direct, Multipass, Multipass with separation of weights, Extended classical modified, Standard, Standard with separation of weights, Classical block, FF, FF1); smoother (Schwarz, Pilut, ParaSails, Euclid); cycle (V, W).

In the material library of the ElmerGUI module are offered the following metals (alloys), liquids, gases, non-metallic materials: air (at room temperature), aluminum, austenitic stainless steel (AK Steel 201), copper, ethanol (at room temperature), fused silica, borosilicate glass, glycerol (at room temperature), gold, iron, lead, oil, platinum, polycarbonate, polyvinyl chloride, silicon, silver, alloy steel, carbon steel, stainless steel, water.

The choice is possible the Cartesian, axi symmetric or cylindrical symmetric coordinate 


\begin{tabular}{|c|c|c|c|c|c|c|}
\hline Impact Factor: & $\begin{array}{l}\text { ISRA (India) } \\
\text { ISI (Dubai, UAF } \\
\text { GIF (Australia) } \\
\text { JIF }\end{array}$ & $\begin{array}{l}=1.344 \\
=0.829 \\
=0.564 \\
=1.500\end{array}$ & $\begin{array}{l}\text { SIS (USA) } \\
\text { PИНЦ (Russia) } \\
\text { ESJI (KZ) } \\
\text { SJIF (Morocco) }\end{array}$ & $\begin{array}{l}=0.912 \\
=0.234 \\
=1.042 \\
=\mathbf{2 . 0 3 1}\end{array}$ & $\begin{array}{l}\text { ICV (Poland) } \\
\text { PIF (India) } \\
\text { IBI (India) }\end{array}$ & $\begin{array}{l}=6.630 \\
=1.940 \\
=4.260\end{array}$ \\
\hline
\end{tabular}

systems for determining the position (displacement) of the models in the graphics window of ElmerGUI. The simulation of steady state, transient and scanning of physical processes is provided.

The materials, the operation conditions and the dimensions of machine parts are selected according to the results of the solution of heat transfer problems. The physical meaning of the heat conduction process is the transfer of thermal energy from a warmer substance to a less heated substance (solid body, liquid or gas) [4]. Heat transfer in the solid bodies is occurred by direct contact or through separating environment. The mathematical description of the heat transfer in solid bodies is represented by the system of equations (1) [5]

$$
\left\{\begin{array}{l}
-k \Delta T=\rho f \\
T=0
\end{array}\right.
$$

where the first equation is the condition for the computational domain of a solid body $\Omega$; the second equation is the condition for the temperature boundary $\Gamma ; \mathrm{k}$ - thermal conductivity, $\mathrm{W} /(\mathrm{m} \cdot \mathrm{K}) ; \mathrm{T}$ - temperature, $\mathrm{K} ; \rho$-density, $\mathrm{kg} / \mathrm{m}^{3} ; \mathrm{f}$ - heat source.

The character of the thermal state of the piston group critical part of an internal combustion engine using computer simulation are researched.

\section{Materials and methods}

The process of heat transfer between the annular groove of the piston and the first compression ring is simulated [6].

For the model of compression piston ring was passed the following dimensions [7]: outer diameter - $65 \mathrm{~mm}$, inner diameter $-60 \mathrm{~mm}$, height $-3 \mathrm{~mm}$ and end gap $-8 \mathrm{~mm}$. 3D model of compression piston ring (to reduce calculation time, the model of the piston was not built) was saved in STEP format [8] to import into the Elmer program.

At import to the file two graphics windows are opened. The first window is displayed a solid model of the ring, the second window - partitioning of the model into finite elements by default. The parameters of the surface triangulation [9] of the model of compression piston ring during merge vertex are accepted deflection which equal to 0.00025 and the feature angle of 30 degrees. The mesh density on surfaces of the model was obtained in the range of $0.005-0.1$.

The partitioning into finite elements solid model of the first compression piston ring is presented in Fig. 1.

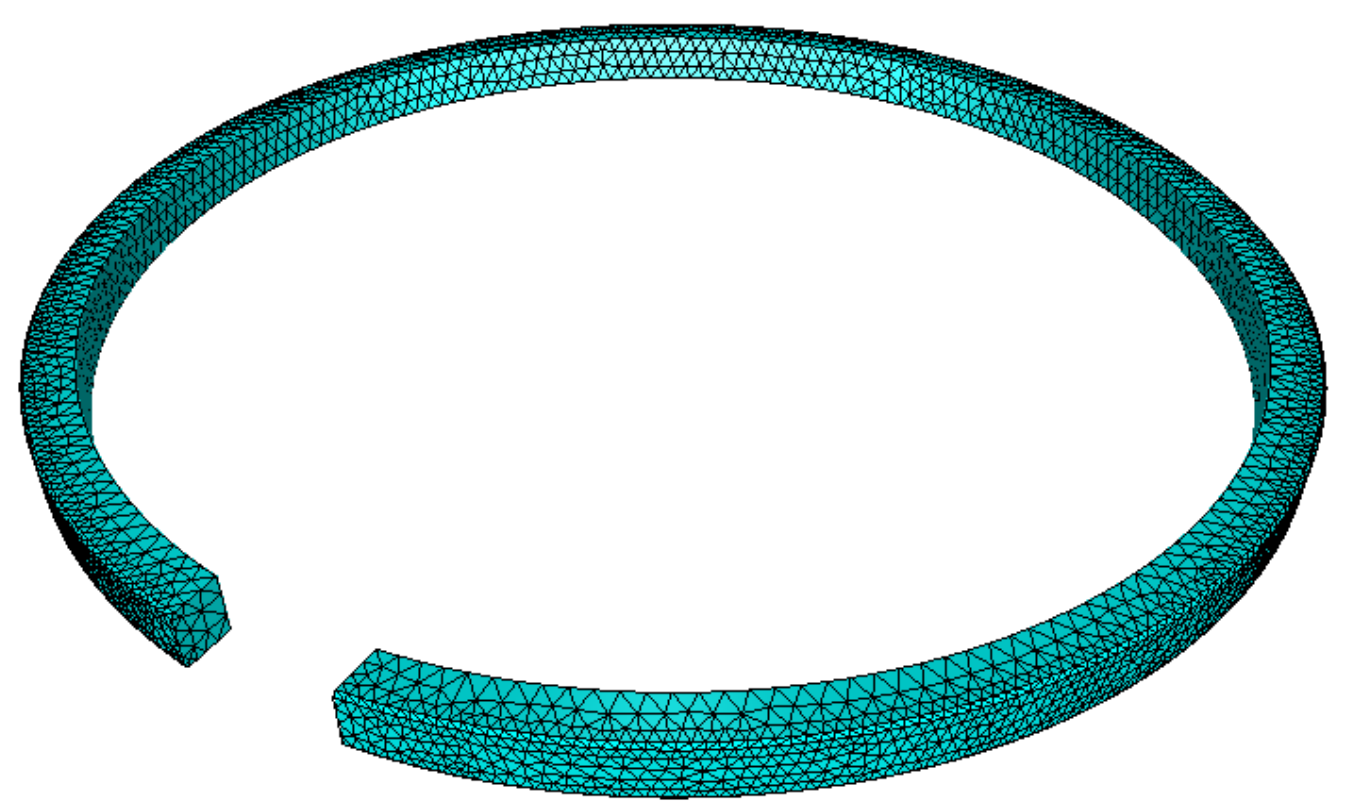

Figure 1 - The partitioning into finite elements solid model of the first compression piston ring.

Below it is the information about results of the partitioning model of the first compression piston ring into finite elements.

FINITE ELEMENT MESH

Mesh dimension: 3

Leading element dimension: 3

Nodes: 5637

Volume elements: 16857
Surface elements: 9786

Edge elements: 14679

Point elements: 0

ELEMENT TYPES

504: 16857

303: 9786

202: 14679

BOUNDING BOX

X-coordinate: [-32.4989, 32.4992]

Y-coordinate: [-32.2529, 32.5]

ISPC Education and Innovation, 


\begin{tabular}{|c|c|c|c|c|c|c|}
\hline Impact Factor: & $\begin{array}{l}\text { ISRA (India) } \\
\text { ISI (Dubai, UAE } \\
\text { GIF (Australia) } \\
\text { JIF }\end{array}$ & $\begin{array}{l}=1.344 \\
=0.829 \\
=0.564 \\
=1.500\end{array}$ & $\begin{array}{l}\text { SIS (USA) } \\
\text { PИНЦ (Russia } \\
\text { ESJI (KZ) } \\
\text { SJIF (Morocco }\end{array}$ & $\begin{array}{r}=\mathbf{0 . 9 1 2} \\
=\mathbf{0 . 2 3 4} \\
=\mathbf{1 . 0 4 2} \\
=\mathbf{2 . 0 3 1}\end{array}$ & $\begin{array}{l}\text { ICV (Poland) } \\
\text { PIF (India) } \\
\text { IBI (India) }\end{array}$ & $\begin{array}{l}=6.630 \\
=1.940 \\
=4.260\end{array}$ \\
\hline
\end{tabular}

Z-coordinate: $[0,3]$

GENERAL

Equations: 0

Materials: 0

Boundary conditions: 0

Body properties: 0

VOLUME BODIES

Body 1: 16857 volume elements

Undetermined: 0

Total: 1 volume bodies

SURFACE BODIES

Undetermined: 0

Total: 0 surface bodies

EDGE BODIES

Undetermined: 0

Total: 0 edge bodies

SURFACE BOUNDARIES

Boundary 1: 1806 surface elements

Boundary 2: 26 surface elements

Boundary 3: 582 surface elements

Boundary 4: 32 surface elements

Boundary 5: 1761 surface elements

Boundary 6: 1797 surface elements

Boundary 7: 762 surface elements

Boundary 8: 762 surface elements

Boundary 9: 1682 surface elements

Boundary 10: 576 surface elements

Undetermined: 0

Total: 10 surface boundaries

EDGE BOUNDARIES

Undetermined: 0

Total: 0 edge boundaries

The first compression piston ring is exposed to significant variable mechanical and thermal loads. The thermal stress of the ring is occurred under the influence of hot working gases and from the friction its on the cylinder wall. The temperature of the first compression piston ring as a result of heating can be achieved $523-573 \mathrm{~K}$.

The conditions simulated stationary process of heat transfer are specified in the tab "Model": the choice of solver, the equation, the material of the first compression piston ring, the type and value of load. The specified conditions are generated in a text file (tab "Sif" $\rightarrow$ Generate $\rightarrow$ Edit).

\author{
Header \\ CHECK KEYWORDS Warn \\ Mesh DB "." "." \\ Include Path "" \\ Results Directory "" \\ End
}

Simulation

Max Output Level $=5$

Coordinate System $=$ Cartesian
Coordinate Mapping(3) = 123

Simulation Type $=$ Steady state

Steady State Max Iterations $=1$

Output Intervals $=1$

Timestepping Method $=\mathrm{BDF}$

BDF Order $=1$

Solver Input File $=$ case. .sif

Post File $=$ case.$e p$

End

\section{Constants}

Gravity (4) = $0-109.82$

Stefan Boltzmann $=5.67 \mathrm{e}-08$

Permittivity of Vacuum $=8.8542 \mathrm{e}-12$

Boltzmann Constant $=1.3807 \mathrm{e}-23$

Unit Charge $=1.602 \mathrm{e}-19$

End

Body 1

Target Bodies $(1)=1$

Name = "Body 1"

Equation $=1$

Material $=1$

Body Force $=1$

End

\section{Solver 1}

Equation $=$ Heat Equation

Procedure = "HeatSolve" "HeatSolver"

Variable $=$ Temperature

Exec Solver $=$ Always

Stabilize $=$ True

Bubbles $=$ False

Lumped Mass Matrix $=$ False

Optimize Bandwidth = True

Steady State Convergence Tolerance $=1.0 \mathrm{e}-5$ $1.0 \mathrm{e}-7$

Nonlinear System Convergence Tolerance $=$

Nonlinear System Max Iterations $=20$

Nonlinear System Newton After Iterations = 3

Nonlinear System Newton After Tolerance = $1.0 \mathrm{e}-3$

Nonlinear System Relaxation Factor $=1$

Linear System Solver = Iterative

Linear System Iterative Method = BiCGStab

Linear System Max Iterations $=500$

Linear System Convergence Tolerance $=1.0 \mathrm{e}$ -

10

BiCGstabl polynomial degree $=2$

Linear System Preconditioning = Diagonal

Linear System ILUT Tolerance $=1.0 \mathrm{e}-3$

Linear System Abort Not Converged $=$ False

Linear System Residual Output $=1$

Linear System Precondition Recompute $=1$

End

\section{Equation 1}

Name = "Heat Equation"

Active Solvers $(1)=1$

ISPC Education and Innovation, 


\begin{tabular}{|c|c|c|c|c|c|c|}
\hline Impact Factor: & $\begin{array}{l}\text { ISRA (India) } \\
\text { ISI (Dubai, UAE } \\
\text { GIF (Australia) } \\
\text { JIF }\end{array}$ & $\begin{array}{l}=1.344 \\
=0.829 \\
=0.564 \\
=1.500\end{array}$ & $\begin{array}{l}\text { SIS (USA) } \\
\text { PИНЦ (Russia } \\
\text { ESJI (KZ) } \\
\text { SJIF (Morocco }\end{array}$ & $\begin{array}{r}=\mathbf{0 . 9 1 2} \\
=\mathbf{0 . 2 3 4} \\
=\mathbf{1 . 0 4 2} \\
=\mathbf{2 . 0 3 1}\end{array}$ & $\begin{array}{l}\text { ICV (Poland) } \\
\text { PIF (India) } \\
\text { IBI (India) }\end{array}$ & $\begin{array}{l}=6.630 \\
=1.940 \\
=4.260\end{array}$ \\
\hline
\end{tabular}

End

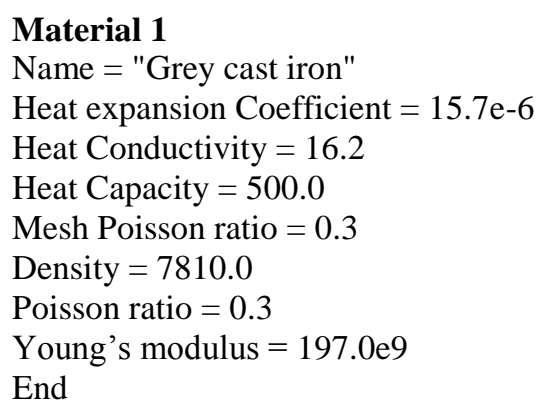

\section{Body Force 1}

Name $=$ "Heating"

Heat Source $=0.01$

End

\section{Boundary Condition 1}

Target Boundaries $(2)=56$

Name $=$ "Temperature"

Temperature $=523.15$

End

Note:

- the thermal load was acted on the upper and lower surfaces of the first compression piston ring;

- BDF - backward differentiation formula.

\section{Results and discussion}

The sequence of calculation of the heat transfer problem is presented in text form with the indication of all performed actions.

ELMER SOLVER (v 8.2) STARTED AT: Date ParCommInit: Initialize \#PEs: 1

MAIN:

MAIN:

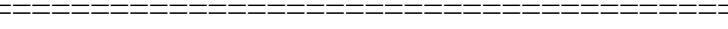

MAIN: ElmerSolver finite element software, Welcome!

MAIN: This program is free software licensed under (L)GPL

MAIN: Copyright 1st April 1995 - , CSC - IT Center for Science Ltd.

MAIN: Webpage http://www.csc.fi/elmer, Emailelmeradm@csc.fi

MAIN: Version: 8.2 (Rev: Release, Compiled: 2016-03-15)

MAIN:

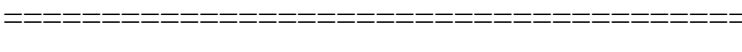

MAIN:

MAIN:

MAIN:

MAIN: Reading Model: case.sif
Loading user function library:

[HeatSolve]...[HeatSolver_Init0]

LoadMesh: Base mesh name: ./.

LoadMesh: Elapsed time (CPU,REAL): 0.2470

$0.2470(\mathrm{~s})$

MAIN:

Loading user function library:

[HeatSolve]...[HeatSolver_Init]

Loading user function library:

[HeatSolve]...[HeatSolver]

OptimizeBandwidth:

OptimizeBandwidth: Computing matrix structure for: heat equation...done.

OptimizeBandwidth: Half bandwidth without optimization: 5591

OptimizeBandwidth:

OptimizeBandwidth: Bandwidth Optimization ...done.

OptimizeBandwidth: Half bandwidth after optimization: 73

OptimizeBandwidth:

MAIN:

MAIN:

MAIN: Steady state iteration: 1

MAIN:

MAIN:

SingleSolver: Attempting to call solver

SingleSolver: Solver Equation string is: heat equation

HeatSolve:

HeatSolve:

HeatSolve:

HeatSolve: TEMPERATURE ITERATION 1

HeatSolve:

HeatSolve:

HeatSolve: Starting Assembly...

HeatSolve: Assembly:

HeatSolve: Assembly done

DefUtils::DefaultDirichletBCs:

Setting

Dirichlet boundary conditions

DefUtils::DefaultDirichletBCs: Dirichlet boundary conditions set

$10.1458 \mathrm{E}+00$

$20.7381 \mathrm{E}-01$

3 0.3473E-01

$40.1327 \mathrm{E}-01$

$50.5964 \mathrm{E}-02$

$60.2916 \mathrm{E}-02$

7 0.1699E-02

8 0.1089E-02

$90.5967 \mathrm{E}-03$

$100.2390 \mathrm{E}-03$

$110.1021 \mathrm{E}-03$

$120.5779 \mathrm{E}-04$

13 0.3407E-04

14 0.1789E-04

$150.9422 \mathrm{E}-05$

ISPC Education and Innovation, 


\begin{tabular}{l|lr|ll|ll} 
& ISRA (India) & $=\mathbf{1 . 3 4 4}$ & SIS (USA) & $=\mathbf{0 . 9 1 2}$ & ICV (Poland) & $=\mathbf{6 . 6 3 0}$ \\
Impact Factor: & ISI (Dubai, UAE) $=\mathbf{0 . 8 2 9}$ & PUHIL (Russia) $=\mathbf{0 . 2 3 4}$ & PIF (India) & $=\mathbf{1 . 9 4 0}$ \\
& GIF (Australia) & $\mathbf{0 . 5 6 4}$ & ESJI (KZ) & $=\mathbf{1 . 0 4 2}$ & IBI (India) & $\mathbf{= 4 . 2 6 0}$ \\
& JIF & $=\mathbf{1 . 5 0 0}$ & SJIF (Morocco) & $=\mathbf{2 . 0 3 1}$ & & \\
\hline
\end{tabular}

16 0.4959E-05

17 0.2495E-05

$180.1295 \mathrm{E}-05$

$190.7065 \mathrm{E}-06$

$200.3758 \mathrm{E}-06$

$210.1834 \mathrm{E}-06$

$220.9445 \mathrm{E}-07$

23 0.5155E-07

24 0.2815E-07

$250.1530 \mathrm{E}-07$

$260.8034 \mathrm{E}-08$

27 0.3887E-08

$280.1861 \mathrm{E}-08$

$290.9025 \mathrm{E}-09$

30 0.4262E-09

31 0.1917E-09

$320.8470 \mathrm{E}-10$

32 0.8470E-10

ComputeChange: NS (ITER=1) (NRM,RELC):

(525.24255 2.0000000) :: heat equation

HeatSolve: iter: 1 Assembly: (s) 0.730 .73

HeatSolve: iter: 1 Solve: (s) 0.070 .07

HeatSolve: Result Norm

525.24254563899115

HeatSolve: Relative Change :

2.0000000000000000

HeatSolve:

HeatSolve:

HeatSolve:

HeatSolve: TEMPERATURE ITERATION 2

HeatSolve:

HeatSolve:

HeatSolve: Starting Assembly...

HeatSolve: Assembly:

HeatSolve: Assembly done

DefUtils::DefaultDirichletBCs: Setting
DefUtils::DefaultDirichletBCs:

boundary conditions set

$10.3714 \mathrm{E}-10$

$10.3714 \mathrm{E}-10$

ComputeChange: NS (ITER=2) (NRM,RELC): (525.24255 0.17934745E-11) :: heat equation

HeatSolve: iter: 2 Assembly: (s) 0.711 .44

HeatSolve: iter: 2 Solve: (s) 0.000 .08

HeatSolve: Result Norm

525.24254563804914

HeatSolve: Relative Change :

1.7934745484415029E-012

ComputeChange: SS (ITER=1) (NRM,RELC): (525.24255 2.0000000) :: heat equation

WritePostFile: Saving results in ElmerPost format to file ./case.ep

ElmerSolver: *** Elmer Solver: ALL DONE ***

ElmerSolver: The end

SOLVER TOTAL TIME(CPU,REAL): 3.61 3.61

ELMER SOLVER FINISHED AT: Date

Note:

- NRM,RELC - the solvers of equations;

- CPU,REAL - the average demand of CPU time/real-time on the calculation.

The solution is made on the first computational step (iteration). On the second step - the check of the convergence the solutions of the problems. The combination of these two iterations is linear convergence. The relative change at each step of the solution is presented graphically in Fig. 2.

Dirichlet boundary conditions

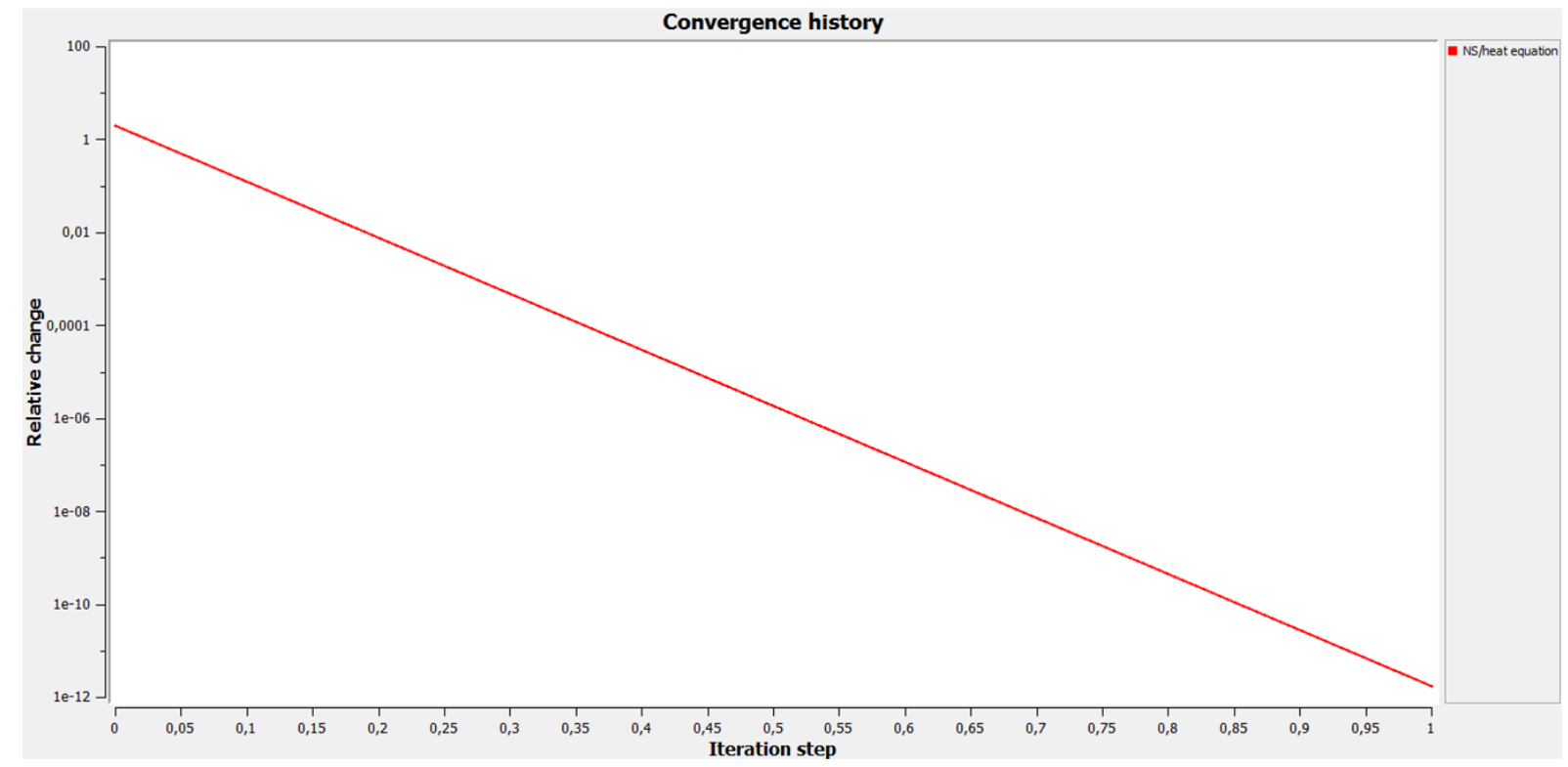

Figure 2 - The convergence graph of the solution.

ISPC Education and Innovation, 


\begin{tabular}{|c|c|c|c|c|c|c|}
\hline Impact Factor: & $\begin{array}{l}\text { ISRA (India) } \\
\text { ISI (Dubai, UAF } \\
\text { GIF (Australia) } \\
\text { JIF }\end{array}$ & $\begin{array}{l}=1.344 \\
=0.829 \\
=0.564 \\
=1.500\end{array}$ & $\begin{array}{l}\text { SIS (USA) } \\
\text { PИНЦ (Russia) } \\
\text { ESJI (KZ) } \\
\text { SJIF (Morocco) }\end{array}$ & $\begin{array}{l}=0.912 \\
=0.234 \\
=1.042 \\
=2.031\end{array}$ & $\begin{array}{l}\text { ICV (Poland) } \\
\text { PIF (India) } \\
\text { IBI (India) }\end{array}$ & $\begin{array}{l}=6.630 \\
=1.940 \\
=4.260\end{array}$ \\
\hline
\end{tabular}

The results of the computer simulation of the heat transfer process are displayed in the ElmerVTK postprocessor module (or in the Start ElmerPost module). The following options of the visual display of calculation results: surfaces, vectors, isocontours, isosurfaces, streamlines are possible.

The calculation result is presented by a vector field of the temperature distribution on the model of the first compression piston ring (Fig. 3).
For the contours 3 parameters are accepted. Length (100) and quality (8) of the vector are set in the dialog window "Controls". The color of vectors when the minimum (maximum) value of the temperature is set in the dialog window "Color". The variable "Temperature" is set in the dialog window "Threshold".

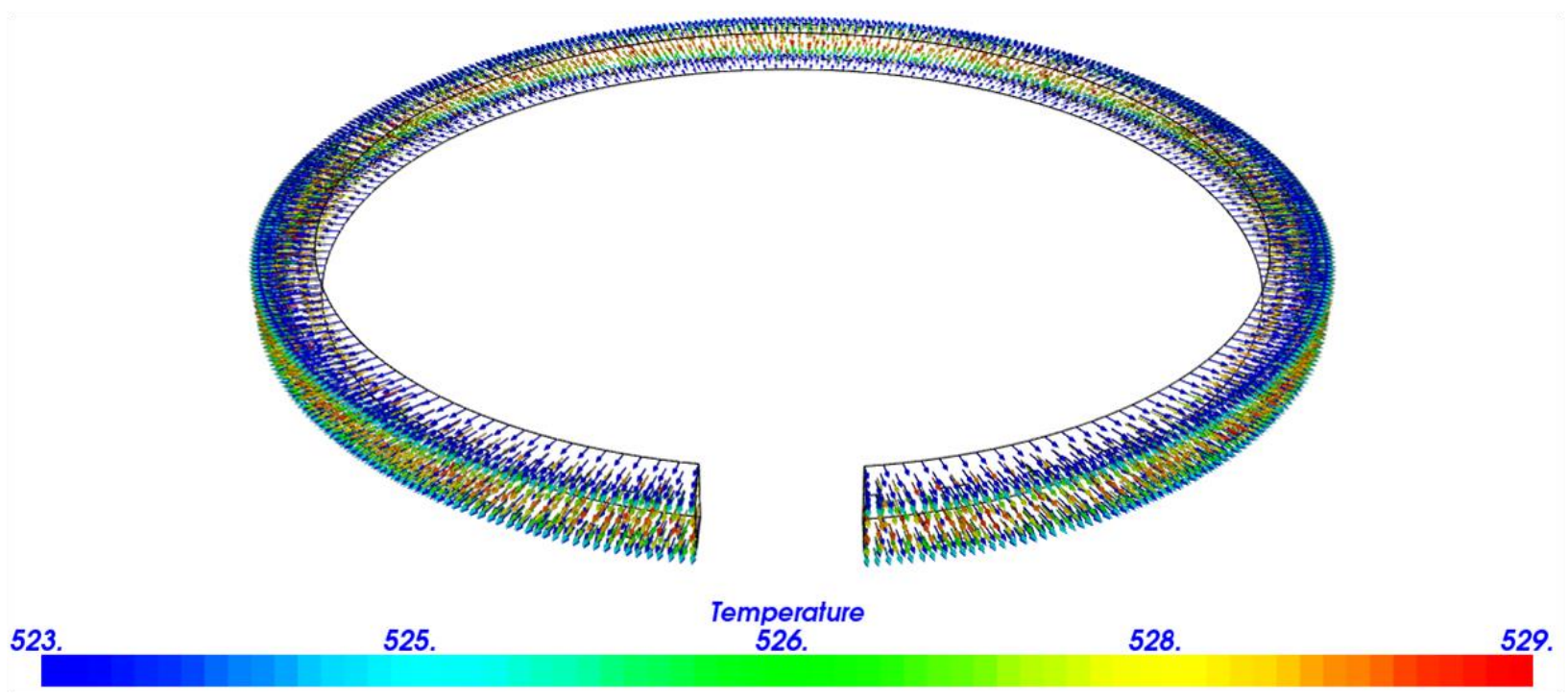

Figure 3 - The temperature field on the model of the first compression piston ring.

The range of the temperature change of the first compression piston ring is amounted $523-529 \mathrm{~K}$. Thermal deformation are exposed to all layers of detail, the most intensely - the middle layers. The contact surfaces of the first compression piston ring are cooled to the minimum temperature. Distribution of heat is occurred from the annular groove of the piston to the cylinder wall. To reduce area of the boundary temperature between the ring and the cylinder wall, the peripheral part of the ring is made spherical. In real conditions the first compression piston ring is made with molybdenum antiwear insert (plasma spraying). This insert is increased the operation period of the ring subject to a quick breakin period.

\section{Conclusion}

The analysis of the results of the computer calculation is showed that the material temperature of the first compression piston ring is increased by $6 \mathrm{~K}$ when acting to a constant heat load. Considered cycle of the heat transfer between the annular groove and the first compression piston ring is characterized by a uniform temperature distribution in the materials of the details under the maximum heat load. To increase the number of the computational steps and to change the value of the temperature of the details will determine the thermal state of the first compression ring per cycle of the operation of the piston.

\section{References:}

1. (2016) Elmer. Available: https://www.csc.fi/web/elmer/elmer (Accessed: 20.11.2016).
2. (2016) Elmer FEM solver. Available: http://www.elmerfem.org/doxygen/index.html (Accessed: 20.11.2016).

3. Elmer GUI Tutorials (2016) CSC - IT Center for Science. $-81 \mathrm{p}$.

ISPC Education and Innovation, 


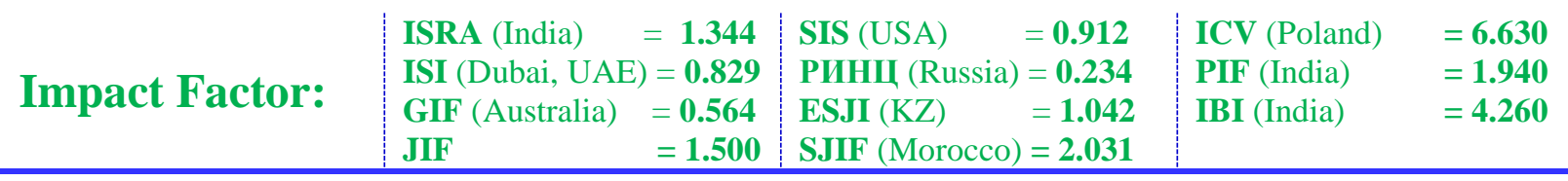

4. (2016) Heat transfer. Available: https://en.wikipedia.org/wiki/Heat_transfer (Accessed: 20.11.2016).

5. (2016) Poisson's equation. Available: https://en.wikipedia.org/wiki/Poisson $\% 27 \mathrm{~s}$ equ ation (Accessed: 20.11.2016).

6. (2016) Piston ring. Available: https://en.wikipedia.org/wiki/Piston_ring (Accessed: 20.11.2016).
7. GOST 621-87. Piston rings for internal combustion engines. General specifications.

8. (2016) ISO 10303. Available: https://en.wikipedia.org/wiki/ISO_10303 (Accessed: 20.11.2016).

9. (2016) Triangulation. Available: https://en.wikipedia.org/wiki/Triangulation (Accessed: 20.11.2016). 